\title{
Competitive Repertoire Complexity: A Potential Mediator in the Upper Echelons Propositions?
}

\author{
Patriciah G. Mwangi ${ }^{1}$, Zachary B. Awino ${ }^{2}$, Kennedy O. Ogollah ${ }^{3} \&$ Ganesh P. Pokhariyal ${ }^{4}$ \\ ${ }^{1}$ Doctoral Candidate, School of Business, University of Nairobi, Kenya \\ ${ }^{2}$ Associate Professor, School of Business, University of Nairobi, Kenya \\ ${ }^{3}$ Lecturer, School of Business, University of Nairobi, Kenya \\ ${ }^{4}$ Professor, School of Mathematics, University of Nairobi, Kenya \\ Correspondence: Patriciah G. Mwangi, P.O. Box 64589-00620 Nairobi, Kenya. E-mail: gachambip@gmail.com
}

Received: August 13, 2018

Accepted: September 2, 2018

Online Published: September 6, 2018

doi:10.5539/ijbm.v13n10p83

URL: https://doi.org/10.5539/ijbm.v13n10p83

\begin{abstract}
This study sought to evaluate the relationships between top management team (TMT) heterogeneity, competitive repertoire complexity and firm performance. The study was grounded on the upper echelons theory which argues that the TMT characteristics affect the organization's performance through their influence on strategic choices. This study sought to investigate this relationship using the complete array of strategies deployed by heterogeneous TMTs. The study was conducted through a cross sectional descriptive survey of 53 large food and beverage manufacturers in Kenya. Primary data and secondary data was collected through a structured questionnaire and checklist respectively and analyzed by descriptive and inferential statistics. The study established that TMT heterogeneity had a significant negative effect on financial, internal processes and social performance in line with the upper echelons theory. Competitive repertoire complexity was not associated with TMT heterogeneity and did not significantly mediate the relationship between TMT heterogeneity and firm performance as expected from the information processing theory. This study contributed to the strategic management field by providing empirical evidence to the upper echelons and resource based view. Managers would benefit by careful consideration of how their TMTs were designed. Policy makers would also be aware about the competitive actions they adopted and their effect on their organizations performance.
\end{abstract}

Keywords: Top management team heterogeneity, Competitive repertoire complexity, Performance, Kenya, upper echelons theory, Food and beverage manufacturing firms

\section{Introduction}

\subsection{Top Management Team Heterogeneity}

The people at the helm of the organization determine its fortunes by influencing its actions and their outcomes. Organizations do not act independently of the people that make them up. The actions and the posture adopted by an organization largely reflect the thought process of its key decision makers. Hambrick and Mason (1984) argued that to understand why organizations behave and perform in a certain way it is important to consider their top executives. They argued that viewing organizations as abstract entities whose outcomes were either planned or unfortunate was not exhaustively insightful because the organization's actions and the success or failure associated with them are as a result of the decisions of their key decision makers.

The top management team (TMT) comprises of the managers at the helm of the organization with whom the overall decision making and running of the organization is vested. They are in charge of the entire organization or its major departments. In a bid to derive the most out of the TMT, organizations incorporate managers with a variety of skills (Ancona \& Caldwell, 1992) with the view that the TMT is able to launch superior strategies leading to organization success. TMT heterogeneity means the differences in the attributes and traits of the senior managers of an organization. It implies that the senior management's characteristics are different from one manager to the next. In this case the TMT is made up of managers with varied attributes. TMT homogeneity on the other hand refers to a situation where the TMT members are alike in their characteristics. Therefore in terms of the characteristics of managers there are few subgroups within the TMT.

Carpenter, Geletkanycz and Sanders (2004) noted that managers provided a useful interface between the 
organization and its environment and their choices affect the organization. Decisions are not made in a vacuum and the decision makers are usually influenced by internal and external factors to arrive at certain conclusions. Carpenter et al. (2004) noted that in dealing with the challenges associated with decision making such as competing goals, ambiguous signals and excess information, executives filter and interpret stimuli based on their cognitive bases and values. This implies that in shifting attention to the TMT in understanding organizations' actions, it is important to get insight into the TMTs' mental processes and value systems. However, Hambrick and Mason (1984) observed that such mental processes and value systems are inconvenient and impossible to measure directly and some important characteristics like tenure do not have psychological equivalents.

Hambrick and Mason (1984) proposed that organizations mirror their senior managers and thus coalesced the upper echelons theory. They noted that while dealing with strategic choices, managers are influenced a great deal by their behavioural components. Operational decisions are amenable to solutions that can computed and thus managers have predetermined codes for dealing with them. Strategic decisions on the other hand do not have existing prescriptions and managers have to design appropriate solutions. These decisions therefore reflect the idiosyncrasies of the decision makers as they try to design appropriate solutions for the non routine situations.

Hambrick and Mason (1984) emphasized application of observable managerial attributes as proxies of the managers' values and mental processes. This is because the managers' cognitive bases and values are shaped by their observable characteristics. Based on their characteristics, managers filter and interpret stimuli in a certain way which influences the choices they make. Managers' observable characteristics therefore influence their decisions. They therefore argued that relatively observable manager attributes like age, functional and socioeconomic roots, tenure, education level and financial status could be useful predictors of strategies and performance.

\subsection{Competitive Repertoire Complexity}

The TMT affects performance through their effect on strategies. They determine the strategies the organization pursues which influence the performance outcomes implying that strategies mediate this relationship. Organizational strategies can be assessed in various ways for instance Porter (1980) defines the generic strategies as either cost leadership or differentiation with a narrow or broad focus. Pearce and Robinson (2012) propose the grand strategies for organizations. Mintzberg (1987) argues that strategy can be seen as a pattern, a plan, a position and a perspective which evolve over time to accommodate reality. Andrews (1980) views strategies at the pattern of decisions that a company makes which reveal its objectives and plans for achieving them. Strategy viewed as a pattern takes into account management's actions over time and allows for evaluation of a wide range of actions that may not fit into certain classes of strategies.

Aligning with the view of strategies as a pattern is the evaluation of the competitive repertoire of an organization. Competitive repertoire focuses on the rivalry between firms pegged on competitive moves and responses, strategic and organizational backgrounds and their drivers and outcomes (Chen \& Miller, 2012). In a bid to improve their positions and performance, firms usually engage in competitive moves ranging from simple actions like price changes to more complex action like integration. Ferrier, Smith and Grimm (1999) defined competitive moves as externally focused, specific and observable actions by a firm to improve or defend its position. Smith, Ferrier and Ndofor (2001) asserted that moves and countermoves in a market resulted in competitive dynamics which mirror the normal and innovative movements in the firm as they pursue profits. They noted that markets never reached equilibrium implying that as long as firms seek to succeed in the marketplace, there will always be competitive moves.

Competitive repertoire implies the array of competitive moves deployed by a firm. It focuses on the entire set of an organization's competitive moves within a certain period which are essential to the competitive arsenal whether minor or major. Chen and Miller (2012) noted that competitive repertoire enables researchers to conceptualize organization strategy in a concrete manner. Lee (2012) conceptualized competitive repertoire as an organization's strategic play book containing a series of unique and sequential actions and counteractions. Miller and Chen (1996) observed that competitive repertoires consisted of set decisions, product or service additions or deletions including major and minor decisions. Lee (2012) noted that to properly analyze the effect of competitive repertoire on performance, it was important to isolate incidental activities from strategically initiated actions. He proposed that only purposely designed actions to achieve competitive advantage should be considered.

Competitive repertoire is a broad construct with several elements to it. Specifically it can be analyzed from the total number of actions undertaken by an organization or from the variety of actions undertaken. Li, Fang, Wang and Lim (2015) suggested that competitive repertoire could be evaluated from three characteristics namely 
volume, complexity and heterogeneity. Volume refers to all the moves launched by a firm within a specific period. It applies to the count of competitive moves undertaken in a certain period. Complexity is the degree to which the continuous competitive actions by a firm are made up of a wide range of actions of different kinds in a given period. Heterogeneity is the degree to which the competitive moves deviate from those of matched competitors.

Competitive repertoire can also be evaluated on a continuum ranging from simplicity to complexity as seen in various studies (Miller \& Chen, 1996; Connelly, Tihanyi, Ketchen, Carnes \& Ferrier, 2017 and Ferrier \& Lyon, 2004). In this case competitive repertoire simplicity refers to the degree to which an organization's competitive actions consist of a narrow set of actions (Ferrier \& Lyon, 2004). Miller and Chen (1996) argued that simplicity comprises of two related aspects that is range and concentration. The range implying that few kinds of actions are used to compete while the concentration refers to only a few kinds of action are employed within the range. They noted that simplicity did not imply that the firm was passive or conservative rather that its decisions are mostly of one type.

Competitive repertoire simplicity works in less turbulent environments where the same actions can prove successful over a period of time. Miller and Chen (1996) argued that managers pursuing simplicity are usually confident to exploit previously successful actions rather than diversify to others. Ferrier and Lyon (2004) noted that simplicity is defended where firms have a distinctive competence that leads to success. However, they observed that there was a fine line between simplicity that leads to success and the one that leads to failure. This is because previously successful strategies when stretched turn to strategic liabilities. Miller (1993) argued that a narrow lens of experience and skewed information processing would predispose the organization to competitive simplicity. Overtime competitive repertoire simplicity therefore leads to failure as the firms fail to maintain appropriate levels of information processing and competitive actions. Miller and Chen (1996) noted that simplicity can be harmful to performance in heterogeneous contexts or in its extremity. This study was on heterogeneous TMTs thus focused on competitive repertoire complexity.

Competitive repertoire complexity refers to a situation where a wide range of competitive moves is engaged and consists of different types of moves. In this case the range of moves is wide and the actions are not concentrated to any type of actions. Connelly et al (2017) noted that as competition progresses, organizations find it necessary to engage rivals with a complicated set of moves. This allows the firm to respond in a better manner to a changing environment and gain competitive advantage. Ferrier and Lyon (2004) noted that firms differ in their repertoire complexity driven by their managers' lens of experience which affects performance differently in the short and long run.

Competitive repertoire complexity is associated with performance especially in the long run. This is because consistent with the resource based view, complex actions make it difficult for rivals to mimic. Offstein (2004) observed that firms' competitive behaviour is important theoretically and empirically since it is linked to financial performance. He argued that competitive repertoire complexity allowed a firm to spread its sources of competitive advantage and maintain it over time. This is because rivals are unable to predict the firm's actions and respond to them. Ndofor, Sirmon and He (2011) established that complexity allowed the firm to use its resources effectively leading to better performance. In addition, competitive repertoire complexity affords a heterogeneous TMT with opportunity to exercise their collective abilities which affects performance. This study therefore sought to explore the upper echelons propositions that the TMT affects performance through its effect on strategic choices using competitive repertoire complexity thereby attempting to create convergence between the upper echelons propositions and the competitive dynamics approach.

\subsection{Firm Performance}

All organizations exist to serve a given purpose whether profit making or not. Firm performance is important to organizations since it usually designates the sole reason for the existence of the firm. Due to this, this construct is valuable to most business managers and management researchers (Richard, Devinney, Yip, \& Johnson, 2009). It is therefore a commonly tested dependent variable in management research (March \& Sutton, 1997). Firm performance is the outcome of organization activities. It is the accomplishment from given actions. March and Sutton (1997) noted that the interest on firm performance as a dependent variable is most explicit in organization strategy since the field defines it as its primary focus. The field seeks to understand, predict and shape organization performance. Venkatraman and Ramanujam (1986) asserted that the value of firm performance in strategic management can be seen in theoretical, empirical and managerial perspectives. From a theoretical perspective, performance is at the heart of strategic management since most theories have performance implications out rightly or inherently. Empirically, most studies use performance to evaluate strategies and 
managers actions. From a managerial perspective most prescriptions are on performance improvement. It is in line with these interests that this variable was adopted by this study.

Several measures have been applied by TMT researchers to measure performance. Carpenter (2002) used return on assets (ROA) to measure firm performance while Lubatkin, Simsek, Ling and Veiga (2006) applied growth in sales, growth in market share, ROE and ROA to measure performance. ROA measures ratio of net operating profit to the firm's assets in the balance sheet. ROA is commonly used to measure accounting performance and is highly correlated with other performance measures such as return on equity (ROE) and return on investment (ROI) (Muchemi, 2013). ROE is derived by dividing the net profit by the book value of shareholders' equity while ROI is the ratio of net operating profit to the net book value of the assets. ROA, ROE and ROI are financial indicators of performance. Growth in sales and growth in market share are largely operational measures relating to the customers perspective. Mutuku (2012) and Awino (2013) used the balanced scorecard (BSC) to measure performance. Kaplan and Norton (1992) noting that financial measures were out of step with the competencies of modern organizations, proposed the BSC which incorporates financial measures and operational measures on customer satisfaction, internal processes and innovation and learning perspectives. Due to this, the BSC is a more comprehensive measure of performance providing a broader perspective of the firm's performance. Hubbard (2009) noted that most organizations that adopted the BSC tended to customize it to their own circumstances. In addition, most of the firms had not reached the level of sophistication required to incorporate the BSC in their organizations. Due to this, he proposed the sustainable balanced scorecard (SBSC) which incorporates social and environmental measures in the BSC. The SBSC incorporates measures that can be easily understood by senior managers and is likely to be more accepted by organizations to measure performance. To accommodate this wider perspective of firm performance, this study adopted the SBSC measures.

\section{Literature Review}

This study was anchored by the upper echelons theory which holds that managers' characteristics determine their choices of strategy and firm outcomes (Hambrick \& Mason, 1984). Therefore, TMT heterogeneity influences organization performance. It was also supported by the resource based view (RBV) and the information processing theory (IPT). RBV argues that firms with valuable, rare and inimitable resources outperform their competitors (Oh \& Kuchinke, 2017; Barney, 2001) whereby TMT heterogeneity and competitive actions are resources that can be deployed for competitive advantage. The IPT holds that people gather information, process it and store it for decision making purposes (Hult, Ketchen, \& Slater, 2004).

Hambrick and Mason (1984) suggested that TMT characteristics determined the strategic choices that the TMT made which determined the performance outcomes. They noted that previous research had tended to exclude the people behind organizational actions. They therefore argued for a shift in focus to the dominant coalition in organizations in order to understand why they acted the way they did. In particular they posited that top managers' characteristics reflected the cognitive bases and values of the managers which they used to make complex decisions. Due to this, top managers' characteristics affected the strategies pursued by the organization and the performance of the organization. These propositions laid the foundation for the upper echelons theory, which many scholars have built on.

Research on TMT and performance has yielded mixed findings. Some authors have found a significant relationship between TMT characteristics and firm performance. Dezso and Ross (2012) using 15 years' panel data from Standard \& Poor's firms studied the link between female representation in the TMT and firm performance. They established that female presence in the TMT led to better performance but only if the firm applied innovation strategy. Certo et al. (2006) in their meta-analysis of 27 empirical studies established that TMT functional heterogeneity and executive tenure heterogeneity had a significant relationship with performance. However they found no relationship for tenure and education heterogeneity with performance. Schwab, Werbel, Hofman and Henriques (2016) studying data collected for all firms by the Portuguese Ministry of Work and Social Solidarity between 1985 to 2000 established that managerial gender diversity affected performance positively. However when gender diversity approached equivalence in management the positive effect declined. This led to the conclusion that there was a curvilinear relationship between managerial gender diversity and firm performance.

Conversely, some scholars have found the relationship between TMT characteristics and firm performance insignificant. Mkalama (2014) analyzing 96 state corporations in Kenya found out that on the overall TMT demographics had a statistically insignificant effect on performance. Specifically age, education, gender and tenure had no significant influence on performance while functional background had a significant impact. In addition all the demographics affected performance positively. Mutuku (2012) surveyed 33 commercial banks in 
Kenya in her study of TMT diversity and firm performance. She determined that there was no significant relationship between diversity in age, gender, tenure in the TMT, academic skills, professional endowment and functional foundations and firm performance. Knight et al. (1999) evaluated the intervening influence of group processes on the relationship between TMT variety and strategic consensus based on 76 high technology firms in USA and Ireland. They found out that functional, educational and tenure differences had a significant effect on strategic consensus while age diversity was insignificant. Functional and educational variations had a negative impact on strategic consensus while tenure variety had a positive one. Consistent with the upper echelons expectations, this study set the first hypothesis:

\section{$H_{1}$ : TMT heterogeneity has no significant effect on firm performance}

Empirical studies suggest that there still exists a gap in understanding when and how TMT heterogeneity affects performance. Certo et al (2006) concluded that there was modest support for a direct association between TMT heterogeneity and firm performance, pointing to the existence of other dynamics to this relationship. Hambrick (2007) noted that the mental and collective processes by which TMT attributes were converted into strategic choices was still obscure. Carpenter (2002) studying 247 large and medium scale organizations in the Standard $\&$ Poor's index noted that the ambiguity of results pointed towards important intervening and moderating variables. He observed that many studies on the upper echelons tended to decontextualize the TMT. He established that TMT education, functional and tenure heterogeneity affected firm performance positively depending on the firm's international strategy. He therefore concluded that TMT researchers needed to be more critical about the conditions under which TMT characteristics affected firm performance.

Hambrick and Mason (1984) in putting together the upper echelons theory argued that the senior executives' characteristics affected corporate performance by affecting the strategic choices they made. In this case strategic choices mediated the upper echelons propositions. Yohannes and Ayako (2016) studied the intervening effect of generic strategies on the relationship between TMT characteristics and performance of Kenyan marketing and social research association firms. They concluded that low demographic diversity was associated with cost leadership which affected performance significantly which was consistent with the upper echelons predictions. Carpenter (2002) concurred that the organizational context is shaped to a great deal by the strategies the organization is pursuing which affects the extent to which TMT heterogeneity affects firm performance. In his study he established that TMT education, functional and tenure diversity affected performance positively depending on the firm's intricacy as shown by the firm's internationalization.

Competitive repertoire provides an avenue for the study of firms' strategies exhaustively by observing their competitive actions over a period of time. Further, TMT heterogeneity is associated with competitive repertoire complexity. Hambrick, Cho and Chen (1996) suggested that senior management profiles could be modified depending on the strategic repertoire of the firm to achieve its objectives. In their study of 32 USA airlines, they established that firms with heterogeneous TMTs had a greater propensity to deploy a wide array of complex competitive moves with a positive impact on performance. However, such firms were slower in responding to competitor's initiatives.

Offstein (2004), in his study of USA pharmaceutical firms between 1999 and 2001, found out that TMT heterogeneity led to competitive moves becoming more complex and sophisticated. He concluded that executive dissimilarity led to an increase in the firm's competitive activity and repertoire complexity. Larraneta, Zahra and Gonzalez (2013) studying 140 new ventures in Spain observed that the new ventures were likely to profit from applying multiple competitive actions especially in highly dynamic industries. Further, they established that in highly uncertain contexts strategic simplicity affected firm performance positively. Ferrier and Lyon (2004) on the other hand, concluded that competitive repertoire simplicity was negatively associated with firm performance among airline firms. However, in their multi-industry study, they established that repertoire simplicity was positively related to performance for firms led by heterogeneous TMTs. These findings imply that heterogeneous TMTs are associated with broader competitive actions leading to positive performance.

Gagnon (2006) studying small and medium sized firms in Quebec also found that TMT characteristics influenced the strategic repertoire. Specifically, he noted that as the TMT became more heterogeneous, the need to gather information grew leading to the development of more information technology applications due to increased complexity. These findings are consistent with the information processing theory whereby a more heterogeneous group has a wider capacity to gather and process information. Connelly et al. (2017) studying 1,168 firms in 204 industries sought to establish the antecedents and performance outcomes of competitive repertoire complexity. They found that complex competitive repertoire is harmful to performance in the short term but beneficial in the long term on condition that the managers do not overexert themselves. However, it can 
overburden the TMT.

Connelly et al. (2017) provide a crucial link between the TMT and competitive repertoire complexity by pointing out that competitive repertoire complexity can overburden the TMT. A heterogeneous TMT has the capacity to handle the burden associated with competitive repertoire complexity due to the variety of skills and experiences provided by the members. Competitive repertoire complexity therefore affects the relationship between TMT heterogeneity and firm performance consistent with the upper echelons theory. Further, the capacity of a heterogeneous TMT to support competitive repertoire complexity is aligned to the information processing theory. This study therefore set the second hypothesis to test this assertion as follows:

$\mathrm{H}_{2}$ : Competitive repertoire complexity has no significant mediating effect on the relationship between TMT heterogeneity and firm performance

In summary, this study therefore sought to test the relationships depicted in figure 1 below.

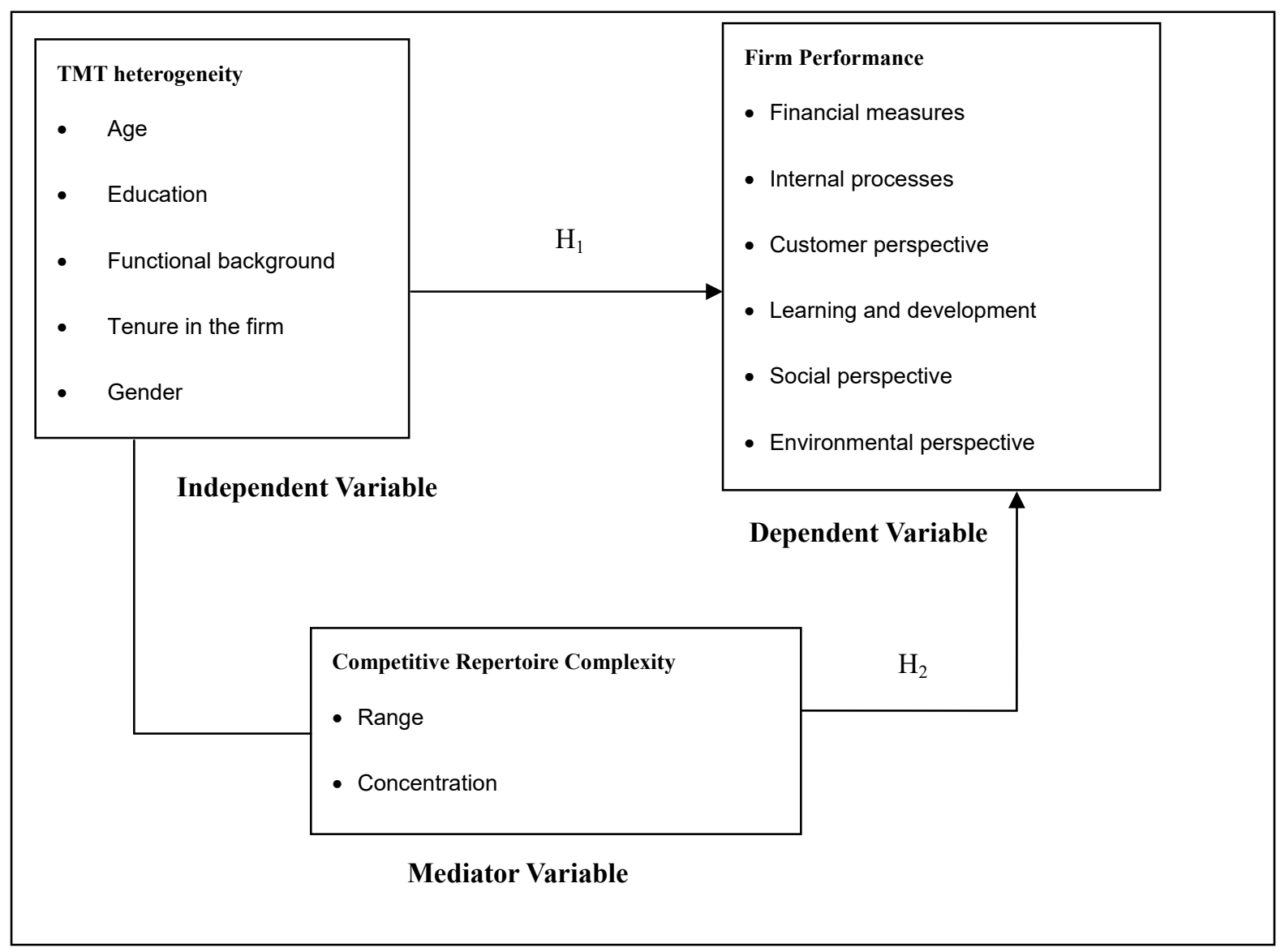

Figure 1. Conceptual Model

\section{Methodology}

The study employed a cross sectional descriptive survey design among food and beverage manufacturing firms since the sector had a large number of established companies run by a team of managers as opposed to a predominantly single manager context. McGrath (2016) noted that 77 out of the global 2000 were from the food and beverage sector while KAM (2016) reported it to be the largest among Kenyan manufacturers. Further to investigate the competitive repertoire of organizations, the study required a context with diverse strategies. Mutunga and Minja (2014) noted that the food and beverage manufacturing sector was one of the most vibrant in Kenya and was also becoming more competitive due to changing consumer trends (Mutunga, Minja, \& Gachanja, 2014). On the other hand, the sampled firms needed to have comparable strategies. The food and beverage manufacturing sector in Kenya therefore provided a viable context for the study. Simple random sampling was applied to select the firms and primary data was obtained from 53 firms through a structured questionnaire while 
secondary data relating to the firms' financial performance was obtained from the Kenya Revenue Authority (KRA).

Heterogeneity measures were calculated from the demographic data collected. For the numerical variables that is age and tenure heterogeneity was measured using the coefficient of variation which has scores ranging from 0 to 1. The closer the score is to 1 the more the variation thus heterogeneous the variable is. The heterogeneity for the categorical variables namely education, functional background and gender was measured using Blau's (1977) heterogeneity index calculated as $1-\sum \mathrm{i}^{2}$ where $i$ is the proportion of the group in the $i$ th category. This index ranges from 0 to 1 where 1 is the highest. This was consistent with other scholars such as Carpenter (2002), Knight et al. (1999) and Hambrick et al. (1996). A composite index for TMT heterogeneity was calculated by getting an average of the individual items. Competitive repertoire complexity was measured using the Herfindahl's index calculated as $\sum\left(\mathrm{a}_{\mathrm{i}} / \mathrm{T}\right)^{2}$ whereby $\mathrm{a}_{\mathrm{i}} / \mathrm{T}$ is the proportion of the firm's actions in the $i$ th category to its total number of actions in a given year (Ferrier \& Lyon, 2004). This index has been applied by Ferrier and Lyon (2004) successfully. Performance measures were then regressed against the composite indices for TMT heterogeneity and competitive repertoire complexity. Simple linear regression was used to evaluate the independent effects of TMT heterogeneity on firm performance while the mediating effect of competitive repertoire complexity was tested through stepwise regression using the Baron and Kenny (1996) model.

\section{Results}

\subsection{TMT Heterogeneity and Firm Performance}

The first objective in this study was to establish the effect of TMT heterogeneity on the performance of large food and beverage manufacturing firms. To examine the first objective, this study set out the first hypothesis, $H_{I}$ : TMT heterogeneity has no significant effect on firm performance which was tested against the six performance perspectives of the SBSC. The results were summarized in Table 1.

Table 1. TMT Heterogeneity and Firm Performance

\begin{tabular}{lllllll}
\hline Performance & R & R square & F & Sig. & B & Conclusion \\
\hline Financial & 0.275 & 0.076 & 4.169 & 0.046 & -1.666 & Significant \\
Customer & 0.134 & 0.018 & 0.934 & 0.338 & -1.4 & Not Significant \\
Internal Processes & 0.311 & 0.097 & 5.236 & 0.026 & -3.006 & Significant \\
Learning \& Development & 0.071 & 0.005 & 0.261 & 0.612 & -0.614 & Not Significant \\
Social & 0.317 & 0.1 & 5.687 & 0.021 & -4.063 & Significant \\
Environmental & 0.176 & 0.031 & 1.637 & 0.207 & -2.184 & Not Significant \\
\hline
\end{tabular}

Table 1 revealed that TMT heterogeneity had a statistically significant effect on financial, internal processes and social perspectives of performance. This was evidenced by $p$ values which were less than the critical $p=0.05$. However the effect of TMT heterogeneity on customer, learning and development and environmental perspectives of performance was statistically not significant. Further, TMT heterogeneity had a negative effect on all performance measures as evidenced by the Beta coefficients. The hypothesis that TMT heterogeneity had no significant effect on firm performance was rejected for financial, internal processes and social perspectives of performance.

\subsection{TMT Heterogeneity, Competitive Repertoire Complexity and Firm Performance}

The second objective in this study was to evaluate the effect of competitive repertoire complexity on the relationship between TMT heterogeneity and the performance of large food and beverage manufacturing firms in Kenya. To capture this objective, a second hypothesis was set, $H_{2}$ : Competitive repertoire complexity has no significant mediating effect on the relationship between TMT heterogeneity and firm performance. To test this hypothesis competitive repertoire complexity was measured in terms of competitive repertoire concentration and competitive repertoire range. This hypothesis was tested using the Baron and Kenny (1986) model for testing mediation. The first condition in this model involves regressing the dependent variable against the independent which was met with the first hypothesis. The second condition involves regressing the mediator against the independent variable. The results were as shown in table 2. 
Table 2. TMT heterogeneity and competitive repertoire complexity

\begin{tabular}{llllll}
\hline Performance & R & R square & F & Sig. & Conclusion \\
\hline Repertoire Concentration & 0.126 & 0.016 & 0.821 & 0.369 & Not Significant \\
Repertoire Range & 0.022 & 0 & 0.024 & 0.877 & Not Significant \\
\hline
\end{tabular}

Table 2 revealed that TMT heterogeneity had no statistically significant effect on competitive repertoire complexity implying that the second condition in testing for mediation was not met. The third condition involves regressing the dependent variable against the mediator variable. Competitive repertoire concentration had a significant effect on financial performance with $\mathrm{p}=0.043$ and competitive repertoire range had a significant effect on financial and internal processes performance with $p=0.049$ and $p=0.022$ respectively. However since the second condition was not met, the study failed to reject the hypothesis that competitive repertoire complexity has no significant mediating effect on the relationship between TMT heterogeneity and firm performance.

\section{Discussions and Conclusions}

This study found that TMT heterogeneity affected different dimensions of performance differently. TMT heterogeneity had a statistically significant effect on financial performance. Further, it affected financial performance negatively implying that when the TMT was composed of managers with different characteristics, financial performance declined. This was aligned to the assertions by Knight et al. (1999) that although diversity is portrayed as a positive force which results in performance, it is negative since it hinders strategic consensus which affects performance. This contradicted findings by Awino (2013) who found a positive but statistically not significant relationship between TMT diversity and financial performance of commercial banks. This could be attributed to the contextual differences between commercial banks and food and beverage manufacturers. This study found that TMT heterogeneity had a negative effect on customer performance but this effect was statistically not significant. This was consistent with the findings by Awino (2013) among commercial banks and Kinuu (2014) among firms listed on the Nairobi Securities Exchange. This implied that when performance was measured in terms of the customer perspective of the SBSC, the variety of characteristics in the TMT were not sufficient to affect firm performance.

TMT heterogeneity had a statistically significant effect on internal processes performance. Further, it had a negative effect on internal processes performance. This implied that the more the TMT became heterogeneous the more internal processes performance declined. This was contrary to the findings by Awino (2013) who found the relationship statistically not significant. The relationship between TMT heterogeneity and learning and development performance was negative albeit statistically not significant. This implied that TMT heterogeneity could not account for the variations in learning and development performance. This supported the findings by Awino (2013) among the commercial banks in Kenya. TMT heterogeneity had a negative effect on social performance which was statistically significant. This implied that TMT heterogeneity was harmful to social performance. This could be attributed to the increased differences among the TMT members which would trigger group dysfunctions (Knight et al, 1999), hindering the TMT from tapping into the potential afforded by the variety of skills and experiences within the TMT. Finally, TMT heterogeneity had a negative but statistically not significant effect on environmental performance. This implied that the effect of TMT heterogeneity alone was not sufficient to affect a firm's environmental performance in a statistically significant manner.

On the overall, this study established that TMT heterogeneity had a significant effect on financial, internal processes and social performance measures but the effect was not significant for customer, learning and development and environmental performance which partially supported the findings by Awino (2013), Muchemi (2013) and Mutuku (2012) who found the relationship not significant. This confirmed the upper echelons propositions that the characteristics of the TMT affect the performance of the organization for some performance measures and therefore the senior executives in an organization matter (Hambrick \& Mason, 1984; Hambrick, 2007). Hambrick (2007) noted that since leadership was a shared activity, the characteristics of the leading coalition would enter into the decision making process and thereby the organization's outcomes. The findings that TMT heterogeneity affected performance therefore provided additional empirical evidence to buttress the upper echelons theory.

It is notable that TMT heterogeneity was found to affect all the measures of performance negatively. TMT heterogeneity bestows wider perspectives, cognitive abilities and capacity to solve problems which results in positive effect on performance as demonstrated by Hambrick et al. (1996), Carpenter (2002), Certo et al. (2006), Mkalama (2014) and Njagi (2015). However, TMT heterogeneity can also lead to schisms that make it difficult to share information (Ancona \& Caldwell, 1992) and in some cases create outright acrimony and 
mistrust (Hambrick et al., 1996) thereby becoming a liability to the organization. This study provided further evidence from the large food and beverage manufacturing firms in Kenya that TMT heterogeneity was detrimental to performance. This was aligned with Knight et al. (1999), Hambrick et al. (2015) and Yohannes and Ayako (2016) who found that TMT heterogeneity affected performance negatively. This can be explained by increased conflict and divisions among the TMT when heterogeneity increases which hinders the ability of the TMT to work together to deliver on performance.

This study also inferred that competitive repertoire complexity did not mediate the relationship between TMT heterogeneity and firm performance. This contradicted the findings by Yohannes and Ayako (2016) who found that generic strategies mediated the relationship between TMT characteristics and firm performance. Carpenter (2002) also established that the firm's international strategy mediates the relationship between TMT heterogeneity and performance. This could be attributed to methodological differences in that these studies investigated single and generic strategies as opposed to the entire array of strategies deployed by the firm. When the entire array of competitive actions was considered, the characteristics of the TMT did not fully reflect on the strategic choices. This was however partially supportive of the findings by Hambrick et al. (1996) that heterogeneous TMTs were slower and more unlikely to respond to competitor initiatives.

Further, this study did not support the expectation that TMT heterogeneity would be associated with competitive repertoire complexity as demonstrated by Hambrick et al. (1996), Offstein (2004) and Gagnon (2006). This was attributed to contextual differences given that these studies had been conducted in the USA airlines and pharmaceutical companies and Quebec small and medium sized firm. This study was conducted among large food and beverage manufacturers in Kenya whereby the dynamic environment imposes certain competitive moves adopted by the firms rather than being deliberately chosen by the TMT. The association between TMT heterogeneity and the competitive repertoire assumes that the TMT has to be actively engaged in strategy choice such that the choices will reflect the idiosyncrasies that the TMT brings to the decision situation. Due to the presence of imposed and emergent competitive actions, the TMT characteristics may not enter into the competitive repertoire adopted by the firms thus the lack of relationship between TMT heterogeneity and competitive repertoire complexity. This study therefore corroborated the assertions by Lee (2012) who noted that in order to crystallize the effect of competitive repertoire on performance, it was vital to distinguish between strategically initiated actions from incidental ones.

The expectation in this study in line with the information processing theory was that as the TMT became more heterogeneous the more it was capable of launching a complex repertoire of competitive actions. The information processing theory argues that organizational subunits are faced by uncertainty as a result of their characteristics and so must develop information and process it to deal with the uncertainty (Tushman \& Nadler, 1978). Shaffer and Kipp (2010) noted that different strategies imposed different information needs. Competitive repertoire complexity requires the organization to gather and process a wide array of information which is possible with a heterogeneous TMT since it has a wider capacity than a homogeneous one. This study's findings were not consistent with the information processing theory. This is because TMT heterogeneity did affect competitive repertoire complexity in a statistically significant manner. However, this study confirmed one of limitations associated with the information processing theory. The theory is accused of failing to explain reactive situations or complex contexts where little or no information is available or time for processing (Shaffer \& Kipp, 2010). The context of this study was the large food and beverage manufacturing firms which due to the nature of the sector necessitated emergent competitive actions.

This study concluded that TMT heterogeneity affects firm performance negatively thus confirming the upper echelons proposition. However, the study established that competitive repertoire complexity had no significant mediating effect on the relationship between TMT heterogeneity and firm performance and concluded that TMT heterogeneity did not affect firm performance through their competitive repertoire. Further, competitive repertoire complexity was not associated with TMT heterogeneity among the large food and beverage manufacturing firms. This study concluded that the relationship envisaged in the upper echelons theory did not hold when the complete array of competitive actions by an organization was considered. This was attributed to the existence of many incidental activities within the firm's competitive actions.

This study concluded that competitive repertoire complexity did not mediate the relationship between TMT heterogeneity and firm performance but it had a significant effect on firm performance either independently or as a moderator. However, the process by which it affected performance was not clearly delineated by this study. Finally, the study concluded that TMT heterogeneity and competitive repertoire complexity constitute resources that can be exploited for value as envisioned in the resource based view. Food and beverage manufacturing firms would therefore benefit in paying attention to these variables when trying to improve their performance. 


\section{Implications of the Study}

This study was anchored on the upper echelons theory and the variables were also supported by the resource based view and the information processing theory. Data was collected to provide empirical evidence aligned to these theories. The study established that on the overall TMT heterogeneity had a significant effect on firm performance consistent with the upper echelons propositions. However, the study showed that when the complete array of competitive actions was considered, the relationship did not hold as envisaged in the upper echelons theory. This study demonstrated that TMT heterogeneity and competitive repertoire can be sources of competitive benefit for a firm when properly deployed. This provided empirical backing to the resource based view that firms can derive their competitive benefit by focusing internally. Finally, the study illustrated that competitive repertoire complexity was not associated with TMT heterogeneity consistent with the information processing theory thus highlighting the inability of the theory to explain emergent and imposed competitive actions.

This study determined that TMT heterogeneity had the potential to harm firm performance which would help policy makers in attempting to determine optimal levels of heterogeneity in order to avoid negative effects on the performance. By shedding light on the negative effects of heterogeneity in TMTs, policy makers would be cautious in trying to introduce diversity in management teams. This implied that organizations would need to draft policies for recruitment, selection, training and development that would ensure more balance in the TMT. It would benefit policy makers in the food and beverage manufacturing sector in designing their competitive actions. The study noted that competitive actions in the sector were riddled with incidental activities which had not been strategically initiated by the TMT. Strategists in these firms would therefore benefit from a clear review of their strategic planning process to balance the positive effect on financial performance and the negative effect on other organization performance measures.

This study demonstrated that organizations and specifically human resource managers would require deliberate efforts to ensure that their senior management teams were balanced in terms of managerial characteristics. This study further noted that the environment facing firms in the food and beverage sector was very dynamic and to keep up, a complex repertoire of actions was required in terms of the range and the concentration. Managers would need to design sustainable actions in the face of the dynamic environment. However, the managers needed to be more deliberate in their choice of actions rather than rely on incidental actions.

\section{References}

Ancona, D. G., \& Caldwell, D. F. (1992). Demography and Design: Predictions of New Product Team Performance. Organization Science, 3(3), 321-341. https://doi.org/10.1287/orsc.3.3.321

Andrews, K. R. (1980). The Concept of Corporate Strategy (2nd ed.). USA: Dow-Jones Irwin.

Awino, Z. B. (2013). Top Management Team Diversity, Quality Decisions and Organizational Performance in the Service Industry. Journal of Management and Strategy, 4(1), 113-123. https://doi.org/10.5430/jms.v4n1p113

Barney, J. B. (2001). Resource-based Theories of Competitive Advantage: A Ten Year Retrospective on the $\begin{array}{llll}\text { Resource-based View. Journal of } & \text { Management, 27(6), 643-650. }\end{array}$ https://doi.org/10.1177/014920630102700602

Baron, R. M., \& Kenny, D. A. (1986). The Moderator-Mediator Variable Distinction in Social Psychological Research: Conceptual, Strategic and Statistical Considerations. Journal of Personality and Social Psychology, 51(6), 1173-1182.

Blau, P. (1977). Inequality and Heterogeneity: A Primitive Theory of Social Structure. New York: Free Press.

Carpenter, M. A. (2002). The implications of strategy and social context for the relationship between top management team heterogeneity and firm performance. Strategic Management Journal, 23(3), 275-284. https://doi.org/10.1002/smj.226

Carpenter, M. A., Geletkanycz, M. A., \& Sanders, W. G. (2004). Upper Echelons Research Revisited: Antecedents, Elements and Consequences of Top Management Composition. Journal of Management, 30(6), 749-778. https://doi.org/10.1016/j.jm.2004.06.001

Certo, S. T., Lester, R. H., Dalton, C. M., \& Dalton, D. R. (2006). Top Management Teams, Strategy and Financial Performance. A Meta-Analytic Examination. Journal of Management Studies, 43(4), 813-839. https://doi.org/10.1111/j.1467-6486.2006.00612.x

Chen, M., \& Miller, D. (2012). Competitive Dynamics: Themes, Trends and a Prospective Research Platform. 
Academy of Management Annals, 6(1), 135-210. https://doi.org/10.1080/19416520.2012.660762

Connelly, B. L., Tihanyi, L., Ketchen, D. J., Carnes, C. M., \& Ferrier, W. J. (2017). Competitive repertoire complexity: Governance antecedents and performance outcomes. Strategic Management Journal, 38(5), 1151-1173. https://doi.org/10.1002/smj.2541

Dezso, C. L., \& Ross, D. G. (2012). Does Female Representation in Top Management Improve Firm Performance? A Panel Data Investigation. Strategic Management Journal, 33(9), 1072-1089. https://doi.org/10.1002/smj.1955

Ferrier, W. J., \& Lyon, D. W. (2004). Competitive Repertoire Simplicity and Firm Performance: The Moderating Role of Top Management Heterogeneity. Managerial and Decision Economics, 25(6-7), 317-327. https://doi.org/10.1002/mde.1193

Ferrier, W. J., Smith, K. G., \& Grimm, C. M. (1999). The Role of Competitive Action in Market Share Erosion and Industry Dethronement: A Study of Industry Leaders and Challengers. Academy of Management Journal, 42(4), 372-388. https://doi.org/10.5465/257009

Gagnon, E. (2006). Complexity, Diversity and Heterogeneity: Evidence Linking IT to Firm Performance (Unpublished doctoral thesis). McGill University.

Hambrick, D. C. (2007). Upper Echelons Theory: An Update. Academy of Management Review, 32(2), 334-343. https://doi.org/10.5465/amr.2007.24345254

Hambrick, D. C., \& Mason, P. A. (1984). Upper Echelons: The Organization as a Reflection of Its Top Managers. Academy of Management Review, 9(2), 193-206. https://doi.org/10.5465/amr.1984.4277628

Hambrick, D. C., Cho, T. S., \& Chen, M. J. (1996). The Influence of Top Management Heterogeneity on Firms' Competitive Moves. Administrative Science Quarterly, 41(4), 659-684. http://dx.doi.org/10.2307/2393871

Hubbard, G. (2009). Measuring Organizational Performance: Beyond the Triple Bottom Line. Business Strategy and the Environment, 18(3), 177-191. https://doi.org/10.1002/bse.564

Hult, G. T. M, Ketchen, D. V., \& Slater, S. F. (2004). Information Processing, Knowledge Development and Strategic Supply Chain Performance. Academy of Management Journal, 47(2), 241-253. https://doi.org/10.5465/20159575

Kaplan, R. S., \& Norton, D. P. (1992). The Balanced Scorecard - Measures that Drive Performance. Harvard Business Review, 71-79.

Knight, D., Pearce, C. L., Smith, K. G., Olian, J. D., Sims, H. P., Smith, K. A., \& Flood, P. (1999). Top Management Team Diversity, Group Process and Strategic Consensus. Strategic Management Journal, 20(5), 445-465. https://doi.org/10.1002/(SICI)1097-0266(199905)20:5<445::AID-SMJ27>3.0.CO;2-V

Larraneta, B., Zahra, S. A., \& Gonzalez, J. L. G. (2013). Strategic Repertoire Variety and New Venture Growth: The Moderating Effects of Origin and Industry Dynamism. Strategic Management Journal, 35(5), 761-772. https://doi.org/10.1002/smj.2103

Lee, J. (2012). Formulating Competitive Repertoires - Four Different Types of Competitive Actions. GSTF Journal on Business Review, 2(2), 105-109.

Li, H., Fang, Y., Wang, Y., \& Lim, K. H. (2015). Understanding Competitive Action Repertoire, Strategic Group and Performance of E-marketplace Sellers: A Latent Growth Modeling Approach. Paper presented at the Thirty Sixth International Conference on Information Systems, Fort Worth.

Lubatkin, M. H., Simsek, Z., Ling, Y., \& Veiga, J. F. (2006). Ambidexterity and Performance in Small to Medium Sized Firms: The Pivotal Role of Top Management Team Behavioral Integration. Journal of Management, 32(5), 646-672. https://doi.org/10.1177/0149206306290712

March, J. G., \& Sutton, R. I. (1997). Organizational Performance as a Dependent Variable. Organization Science, 8(6), 698-706. https://doi.org/10.1287/orsc.8.6.698

McGrath, M. (2016). The World's Largest Food and Beverage Companies 2016: Chocolate, Beer and Soda Lead the List. Retrieved from http://forbes.com/sites/maggiemcgrath/2016/05/27/the-worlds-largest-food-and-beverage-companies-2016chocolate-beer-and-soda-lead-the-list/\#23924c76c719

Miller, D. (1993). The Architecture of Simplicity. Academy of Management Review, 18(1), 116-138. https://doi.org/10.5465/amr.1993.3997509 
Miller, D., \& Chen, M. J. (1996). The Simplicity of Competitive Repertoires: An Empirical Analysis. Strategic $\begin{array}{llll}\text { Management } \quad \text { Journal, } & \text { 419-439. }\end{array}$ https://doi.org/10.1002/(SICI)1097-0266(199606)17:6<419::AID-SMJ818>3.0.CO;2-Z

Mintzberg, H. (1987). The Strategy Concept I: Five Ps for Strategy. California Management Review, 30(1), 11-24. https://doi.org/10.2307/41165263

Mkalama, R. N. (2014). Top Management Team Demographics, Strategic Decision Making, Macro-environment and Performance of Kenyan State Corporations (Unpublished Doctoral Thesis). University of Nairobi, Kenya

Muchemi, A. W. (2013). Top Management Team Diversity and Performance of Commercial Banks (Unpublished Doctoral Thesis). University of Nairobi, Kenya

Mutuku, C. M. (2012). Factors Influencing Relationship between Top Management Team Diversity and Performance of Commercial Banks in Kenya (Unpublished Doctoral Thesis). University of Nairobi, Kenya.

Mutunga, S. L., \& Minja, D. (2014). Generic Strategies Employed by Food and Beverage Firms in Kenya and Their Effects on Sustainable Competitive Advantage. International Journal of Business and Management Review, 2(6), 1-15.

Mutunga, S. L., Minja, D., \& Gachanja, P. (2014). Resource Configurations on Sustainable Competitive Advantage of Food and Beverage Firms in Kenya: A Resource Based View of the Firm. European Journal of Business and Management, 6(24), 147-157.

Ndofor, H. A., Sirmon, D. G., \& He, X. (2011). Firm Resources, Competitive Actions and Performance: Investigating a Mediated Model with Evidence from the In-Vitro Diagnostics Industry. Strategic Management Journal, 32(6), 640-657. https://doi.org/10.1002/smj.901

Njagi, E. M. (2015). Relationship between Top Management Team Diversity and Performance of Oil Marketing Companies in Kenya (Unpublished MBA Thesis). United States International University.

Nourayi, M. M., \& Daroca, F. P. (1996). Performance Evaluation and Measurement Issues. Journal of Managerial Issues, 8(2), 206-217.

Offstein, E. H. (2004). The Upper-Echelon Perspective of Firm Competitive Behavior: Empirical Evidence from the U.S. Pharmaceutical Industry (Unpublished Doctoral Thesis). Virginia Polytechnic Institute and State University

Oh, S. Y., \& Kuchinke, K. P. (2017). Exploring the role of organizational learning activities in the quality management context. Leadership \& Organization Development Journal, 38(3), 380-397. https://doi.org/10.1108/LODJ-11-2015-0259

Pearce, J. A., \& Robinson, R. B. (2012). Strategic Management: Planning for Domestic \& Global Competition. USA: McGraw-Hill Education.

Porter, M. E. (1980). Competitive Strategy: Techniques for Analyzing Industries and Competitors. New York: Free Press

Richard, P. J., Devinney, T. M., Yip, G. S., \& Johnson, G. (2009). Measuring Organizational Performance: Towards Methodological Best Practice. Journal of Management, 35(3), 718-804. https://doi.org/10.1177/0149206308330560

Schwab, A., Werbel, J. D., Hofmann, H., \& Henriques, P. L. (2016). Managerial Gender Diversity and Firm Performance: An Integration of Different Theoretical Perspectives. Group \& Organization Management, 41(1), 5-31. https://doi.org/10.1177/1059601115588641

Shaffer, D. R., \& Kipp, K. (2010). Developmental Psychology. USA: Cengage Learning.

Smith, K. G., Ferrier, W. J., \& Ndofor, H. (2001). Competitive Dynamics Research: Critique and Future Directions. In Hitt, M. A., Freeman, R. E., Harrison, J. R. (Eds.), Handbook of Strategic Management (pp. 315-361). Blackwell: Oxford, UK,. https://doi.org/10.1111/b.9780631218616.2006.00012.x

Tushman, M. L., \& Nadler, D. A. (1978). Information Processing as an Integrating Concept in Organization Design. Academy of Management Review, 3(3), 613-624. https://doi.org/10.5465/amr.1978.4305791

Venkatraman, N., \& Ramanujam, V. (1986). Measurement of Business Performance in Strategy Research: A Comparison of Approaches. Academy of Management Review, 11(4), 801-814. https://doi.org/10.5465/amr.1986.4283976 
Yohannes, T. H., \& Ayako, A. B. (2016). Top Management Team Demographic Diversities, Generic Strategy and Firm Performance in Marketing Social Research Association (MSRA) in Kenya. Applied Finance and Accounting, 2(2), 30-45. https://doi.org/10.11114/afa.v2i2.1586

\section{Copyrights}

Copyright for this article is retained by the author(s), with first publication rights granted to the journal.

This is an open-access article distributed under the terms and conditions of the Creative Commons Attribution license (http://creativecommons.org/licenses/by/4.0/). 